\title{
Politeness strategies in the job application letter: Implications of Intercultural Rhetoric for designing writing feedback
}

\section{Dacia Dressen-Hammouda}

\section{OpenEdition}

Electronic version

URL: http://journals.openedition.org/asp/3866

DOI: $10.4000 /$ asp.3866

ISSN: 2108-6354

\section{Publisher}

Groupe d'étude et de recherche en anglais de spécialité

Printed version

Date of publication: 1 November 2013

Number of pages: 139-159

ISSN: 1246-8185

\section{Electronic reference}

Dacia Dressen-Hammouda, « Politeness strategies in the job application letter: Implications of Intercultural Rhetoric for designing writing feedback », ASp [Online], 64 | 2013, Online since 01

November 2014, connection on 02 November 2020. URL : http://journals.openedition.org/asp/3866 ; DOI : https://doi.org/10.4000/asp.3866

This text was automatically generated on 2 November 2020 .

Tous droits réservés 


\title{
Politeness strategies in the job application letter: Implications of Intercultural Rhetoric for designing writing feedback
}

\author{
Dacia Dressen-Hammouda
}

1 To improve non-native English (NNE) student writing in the ESP classroom, many second-language (L2) writing pedagogies today rely on written teacher feedback. However, considerable debate persists over the effectiveness of feedback in inducing progress in NNE student writing, especially if that feedback is grammar-based. Despite decades of research, positions are polarized, with some researchers (Bitchner \& Knock 2009; Truscott 2007, 2010; Truscott \& Hsu 2008) arguing that grammar error correction has little or no long-term effect on NNE writing accuracy, while others (Chandler 2003; Ferris 2004; Ferris et al. 2013) argue to the contrary.

2 One reason why writing feedback research may have produced such conflicting results is that it has often focused narrowly on a single aspect of NNE writing: grammar error. It can be argued, however, that focusing solely on grammatical error as a measure of writing progress is an unreliable indicator of improvement. Indeed, earlier Second Language Acquisition research has suggested that NNE learners in the process of acquiring new linguistic forms may perform them accurately on one occasion but may fail to do so on similar, later occasions (see Ferris 2004 for discussion). In addition, NNE writers must master a whole range of competencies, which includes grammar but also knowledge about the features of register, rhetoric, situation, subject-matter, genre, culture and identity.

In this regard, what helps or hinders the improvement of NNE writing is something quite subtle and long-term, tied up with issues of genre and rhetorical knowledge, process, prior experience, mentoring and participation, identity, shifting roles in genre networks, and access to resources (Tardy 2009). In this context, NNE writers' 'language errors' are an interesting indication of a far more complex process at work. 
4 Not only is the NNE writer's situation irreducible to surface language errors, but the feedback teachers give in return is never wholly objective. Instead, as an increasing number of writing researchers have shown, writing feedback must be understood as constructed within "particular cultural, institutional, and interpersonal contexts, between people enacting and negotiating particular social identities and relationships" (Hyland \& Hyland 2006: 10). Indeed, a wide range of studies have shown that NNE writing is often evaluated against the standards of the teacher's own culture (Davies et al. 2003; Hyland \& Anan 2006; Ivanič \& Camps 2001; Ramanathan \& Atkinson 1999; Rubin \& Williams-James 1997; Zhao \& Llosa 2008). The ensuing comparison feeds into a 'discourse of deficit' model implicitly associated with NNE writing which, when left unchallenged, assumes that the distinctive, non-standard language patterns of NNE writing are simply 'mistakes' which need fixing. However, truly effective feedback needs to go beyond identification of error to uncovering why NNE writers are making such 'errors' in the first place. Okamura and Shaw (2000), for example, have underscored the observation that while NNE writers do perceive the rhetorical demands of situation, they are less likely to use expected language to respond to those demands. Effective writing feedback must also consider reasons why NNE writing may not be meeting L2 writing instructors' expectations.

For some time, of course, the role a writer's first language culture plays in shaping their second language writing has been considered a central aspect of L2 writing pedagogy and research. Starting with Kaplan's (1966) seminal work on "writing cultures" and cultural thought patterns, such research has led to the development of the fields of Contrastive Rhetoric (Connor 1996) and Intercultural Rhetoric (Connor 2004, 2011; Belcher \& Nelson, 2013). More recently, Connor (2011) explains how the term 'intercultural' has come to replace the term 'contrastive'. She considers 'intercultural' as more appropriate to investigating NNE rhetoric and writing today because it better captures a state of being "within, in the midst of, [in a] mutual [space] of reciprocal intermingling" (2011: 1) than 'contra-', which acts "in opposition to something, with no middle ground" (2011: 2). The concept of 'intercultural' in Intercultural Rhetoric highlights

the importance of considering language and writing as social actions within particular contexts as well as the crucial move of understanding intercultural communication as an act of interaction and accommodation between native speakers and non-native speakers - not one of assimilation by non-native speakers of English. (Connor 2011: 7, emphasis added)

Intercultural Rhetoric (IR) thus provides a valuable framework for designing more effective writing feedback because it strongly implies that mere language correction and emphasis on teaching English language norms are insufficient to improve effectiveness in NNE writing. A word of caution at this point is in order, however: clearly, an IR approach does not argue for eliminating the teaching of cultural and linguistic norms, which by all accounts would be irresponsible (Connor 2011; Swales 2004; Hyland 2008). It does, however, invite a much greater sensitivity to the multiple contexts at play in the language classroom, recognizing the inherent 'interdiscursivity' of social practice (Bhatia 2008). It opens the door - a bit more widely, perhaps - to accounting for the fact that successfully learning and using native English speakers' linguistic and rhetorical norms poses complex challenges to NNE writers, and teaching them must be resituated and framed within NNE writers' own needs and socio-cultural situations and institutions. 
7 The purpose of the current study is to describe how combined quantitative and qualitative results from IR analysis may be used to design more effective writing feedback. It applies genre-based move analysis and a lexico-grammatical text analysis to a "local learner corpus" (Seidlhofer 2002) of 69 job application letters written by native French-speaking students in an undergraduate ESP course. The use of learner corpora in SLA and writing research is a growing area (Granger, Hung \& Petch-Tyson 2002; Connor \& Upton 2004), instigating applied corpus linguists to work from the viewpoint of actual teachers and learners. This study's learner corpus was constituted to examine the students' use of politeness strategies, whose relative success or failure was further evaluated by eight native-English speakers. ${ }^{1}$ To better understand why students chose to express these strategies in the way they did, the study also qualitatively describes the student writers' viewpoint on politeness expectations, following Flowerdew's (2010) suggestions for carrying out 'present situation analysis' of student needs. It thus resituates the corpus features within the rhetorical and cultural context of the students' L1 politeness norms. The next section discusses general aspects of politeness, and establishes the background for the analysis by briefly comparing politeness strategies in French and English job application letters. After discussing the methodology and results, it concludes with a discussion of how IR analysis might be used to improve the design and effectiveness of writing feedback.

\section{Politeness strategies}

Lakoff's (1973) classic paper describes the socio-cultural function of politeness as helping people to alleviate and avoid the risks associated with interaction conflict. Like Brown and Levinson (1987), Lakoff views politeness as smoothing over the rough edges of social interaction, which creates potential risks for interactants: of being constrained, embarrassed, humiliated, or threatened. Politeness makes the interaction less abrasive and hurtful as a result of using indirectness, softeners, or mitigators.

Brown and Levinson's (1987) politeness model formalizes the universal role politeness plays for this purpose. Their model proposes that individuals have two 'faces' which are inevitably threatened when people interact. One's positive face reflects the need to be accepted and to belong, and attempts to highlight the shared goals and expectations held in common with the addressee. One's negative face reflects the desire to act without being hindered by others, and indicates that one does not intend to impede the addressee's freedom of action. What makes this balance particularly challenging for NNE writers is that the nuances of the linguistic devices that organize 'face' can vary significantly from culture to culture.

10 Using Brown and Levinson's politeness model, a number of ESP studies have explored how NNE writers manage politeness strategies in various genres, such as the job application letter. Maier (1992), for example, has compared job application letters written by native and non-native (i.e., Japanese) English speakers. She examined their use of Brown and Levinson's (1987) positive (showing interest, offering a contribution or benefit, being optimistic) and negative politeness strategies (apologizing, going on record as incurring a debt, being pessimistic, being indirect, giving deference). She found that native speakers used more deferential and negative politeness strategies than non-native speakers, lessening the imposition of their requests with a greater use of modals and indirectness. In contrast, non-native writers used "potentially risky 
positive politeness strategies" (Maier 1992: 203) and wrote using an informal and direct language that could be perceived as rude and even disrespectful.

11 Upton and Connor (2001) built on Maier (1992) by examining a learner corpus of job application letters written by non-native speakers of English (Finns and Belgians) and native speakers (Americans). They analyzed the lexico-grammatical patterns of politeness strategies from two genre moves associated with the job application letter: 'requesting an interview' (Move 4), and 'giving thanks for consideration' (Move 5; see Table 1). They found that in these two moves, American writers used many formulaic expressions for communicating both positive and negative politeness, whereas the Belgian writers' (Flemish-speaking; U. Connor, personal communication) style was more heterogeneous and personal, with Finnish writers falling somewhere in between.

Table 1 Genre moves of the 'Learner application letter'

1. Identify the source of information (Explain how and where you learned of the position).

2. Apply for the position (State desire for consideration).

3. Provide argument, including supporting information, for the job application.

a) Implicit argument based on neutral evidence or information about background and experience.

b) Argument based on what would be good for the hiring company (My intercuitural training will be an asset to your international negotiations team').

c) Argument based on what would be good for the applicant ('This job will give me the opportunity to test my intercultural training').

4. Indicate desire for an interview or a desire for further contact, or specify means of further communication/how to be contacted.

5. Express politeness (pleasantries) or appreciation at the end of the letter.

6 . Offer to provide more information.

7. Reference attached résumé.

from Upton \& Connor 2001: 318

Given that the non-native participants of both studies were enrolled in advanced courses of English for international business, one could assume that their linguistic capacities did not hinder their ability to adequately express the appropriate message required for writing job application letters. Rather, what appears to be the issue is the writers' lack of knowledge about cultural appropriateness, which caused them to produce less formal and more direct letters in this particular writing context.

Building on these earlier works, the current study describes the politeness strategies used by native French-speaking (NF) undergraduate writers for requesting and thanking in the job application letter in English. It expands on both Maier (1992) and Upton and Connor (2001) by proposing a more culturally-situated explanation for the particular politeness violations NF writers make in this writing situation. Such a focus is important because it may better reveal why NNE writers' strategies diverge from expected norms, allowing for more sensitive writing feedback that goes beyond treating divergence as 'deficit'. While Upton and Connor (2001) did not explain why they chose to focus only on Move 4 ('requesting an interview') and Move 5 ('giving thanks for consideration'), in fact a focus on the acts of requesting and thanking is important for the NF writers in this study because, as both the quantitative and qualitative analyses show, these acts posed particular problems for the study participants. 


\subsection{Intercultural differences in politeness strategies} in part, by Kerbrat-Orecchioni's (2011) arguments for expanding on Brown and Levinson's politeness model. Based on her diachronic research on politeness strategies in French, Kerbrat-Orecchioni has argued that viewing politeness solely as deflecting 'face-threatening acts' is misleading, because politeness is about more than just repairing threats. It also includes 'anti-threats': people work to save face and enhance it. Accordingly, she proposes 'face-flattering acts' (or FFAs, also 'face-enhancing' or 'face-giving') as a counterpoint to face-threatening acts (FTAs). Whereas FTAs are softened (through indirectness and reductors), FFAs are reinforced (thanks a lot/very much/a million) but never diminished (thanks a little). Kerbrat-Orecchioni's diachronic model highlights the enduring nature of such politeness structures, noting that "the profound logic that politeness obeys [in French] is the same in all eras" (KerbratOrecchioni 2011: 133). Earlier constrastive studies, such as Maier (1992), did not make such a distinction, thereby missing an opportunity to better understand the strategic choices NNE writers might make in the job application letter.

Even so, FFAs are historically significant. Held (1999), for example, has examined the large number of lexico-grammatical politeness markers historically associated with the acts of requesting and thanking. Requesting, for example, requires the speaker to carry out an act which can directly threaten the hearer's territory or face. Requests are therefore inherently impolite and potentially face-threatening, and speakers must counter them by drawing on a number of strategies. In contrast, thanking is an inherently polite speech act. It seeks to restore the balance between speaker and hearer after the exchange of some 'gift'. For Held, both pose particular problems to the speaker's self-presentation because the situations which create them do not just 'go away' automatically and thus require the speaker to pro-actively re-balance the sociorelational space between speaker and addressee.

To restore this balance, Held focuses specifically on the role played by "gestures of submission", which she situates within the historical context of French, Italian, German and English. For Held, a gesture of submission is "any type of self-withdrawal, selfdenigration and personal submission in favour of the interactional partner, which a polite individual is constrained to perform for social-ethical reasons" (1999: 21). Gestures of submission are essentially face-flattering (Kerbrat-Orecchioni 2011), a negative politeness strategy which emerged within the rigidly hierarchical social relationships born of the feudal system of the Middle Ages, whereby the less powerful paid homage to the more powerful. Over time, increasing democratization caused the act of "paying respect to rank" (1999: 23) to shift more toward a focus on one's personal value than on one's social status. For Held, gestures of submission "are a type of higher, civilised behaviour. [...]. [They create] a reciprocal obligation to exchange mutual face wants so that the assignment of power and claims to power can be carried out on a mutual basis" (Held 1999: 24).

ased on her examination of historical French, Italian, and English, she suggests a typology of gestures of submission in the acts of thanking and requesting. The devices identified for thanking include, for example, giving evidence of dependency, confusion and embarrassment, of being unable to reciprocate, and of regret for the cost and inconvenience incurred by the giver. For requesting, she has identified devices of 
indeterminacy, quantitative and durative restrictions, diminutive processes, epistemological hedges, moralizing and admitting one's intrusion.

Interestingly for the purposes of the current study, Held identifies letters as a key genre in which gestures of submission still work to mitigate interactional conflict because letters, as a written medium, tend to conservatively retain certain "respect rituals" better than oral discourse. As she notes, "The beginnings and ends of letters... are still negotiated - in accordance with the conventions of the culture concerned with an inventory of fixed [gestures of submission]" (1999: 26). Speakers rely on this inventory to reify their apparent subordination to a socially superior addressee, thereby engaging in polite 'face-flattery' (Kerbrat-Orecchioni 2011). Held's principal argument is that gestures of submission still play a central role in letter writing, allowing writers to repair the more difficult relational problems engendered by requesting and thanking by maintaining 'social respect' for the addressee's negative face.

\subsection{Politeness strategies in French and English application letters}

Ritualized gestures of submission appear to still play an important role in French business letter writing. In contrast, the use of gestures of submission in different varieties of English business letters appears to have diminished considerably. To illustrate this point, Table 2 shows a very summary comparison of six job application letters ( 3 in French, 3 in American English), focusing on Upton and Connor's (2001) Move 4 ('requesting an interview') and Move 5 ('giving thanks for consideration'). The French job application letters are accessible to job seekers via the French government's centralized unemployment agency ('Pôle emploi'), whereas the American English job application letters are taken from do-it-yourself job preparation websites found on the Internet.

Table 2 Examples of requesting and thanking in French and American English job application letters

Espérant que ma candidature retienne votre attention je me tiens à votre entière disposition afin de vous démontrer mes motivations et mes perspectives d'avenir au cours d'un entretien. Dans l'attente d'une réponse de votre part, veuillez, agréer, Monsieur, l'expression de mes salutations distinguées.

Dans l'attente d'une réponse de votre part, je me tiens à votre entière disposition pour de plus amples informations et vous prie de croire, Monsieur, en l'expression de toute ma considération.

Je vous remercie de l'attention que vous voudrez bien porter à l'examen de mon dossier et reste à votre entière disposition pour toute information complémentaire ou rendez-vous qu'il vous conviendra de me proposer. Dans l'attente de ce contact, veuillez agréer, Monsieur, l'expression de mes salutations distinguées. 
With the combination of the academic and professional experiences, I am looking forward to discussing the opportunity to join your organization. Your consideration of my qualifications for the Business Analyst position is appreciated and I look forward to the next step in the hiring process.

Please contact me after $6 \mathrm{pm}$ at the above number to schedule an interview. Thank you for your consideration.

I am very interested in becoming a part of this project after reading an article in the Civil Engineering Journal about your company's involvement in building a new mall in the area. I can be reached at the address and phone number below. I will be calling your office within ten days to inquire on the status of my application. I look forward to hearing from you.

Although it is not my purpose to carry out an in-depth IR analysis of these letters' rhetorical and linguistic differences, Table 2 illustrates how, in comparison to American English, contemporary French business letters seem to maintain more gestures of submission in their politeness strategies. One can note, for example, the highly ritualized and formulaic nature of requesting an interview in French, as seen in the frequent use of expressions such as 'je reste à votre [entière] disposition' (Move 6 in Upton \& Connor 2001), always associated with the interview request of Move 4, and the formulaic evidence of social dependency used to express one's appreciation for further contact ('veuillez agréer/je vous prie de croire à l'expression de ... mes salutations distinguées/ toute ma considération'). In addition, the interview request in French is often embedded in a noun phrase emphasizing the addressee ('votre attention', 'une réponse de votre part') and indicates a temporality which stresses the reader's space ('dans l'attente de [votre réponse]'). If a writer makes the request more explicit ('rendez-vous'), the weight of the imposition can be lessened immediately with a submissive stance ('qu'il vous conviendra de me proposer'). The overall impression of the persona portrayed in the French job application letter is one where the writer places her/himself below the reader, implicitly leaving the initiation of any further action up to the reader. Such negative, face-flattering politeness strategies appear to be in close alignment with the acts of "self-withdrawal, self-denigration and personal submission in favour of the interactional partner" (Held 1999: 21) associated with social gestures of submission. Here, the need to demonstrate face-flattering strategies leads the writer to reinforce the space allotted to the reader.

21 In the American English job application letters, in contrast, reader-flattering gestures of submission appear to have given way to formulaic expressions of writer-oriented pro-activeness: writers do not indicate that they will wait for the reader's uptake, but instead demonstrate their willingness to take responsibility for actively pursuing further contact, softening the face-threatening potential of the interaction by deflecting attention away from the reader back toward the writer: 'I am looking forward to discussing the opportunity to join your organization', 'I am very interested in becoming a part of this project... I will be calling your office within ten days to inquire on the status of my application'. The request for further contact appears to be more writer than readerbased and is communicated through verbal, rather than nominal, strategies ('Please contact me after 6 pm', 'I can be reached at the address given below'); in each case the writer appears to take the initiative for inducing a response. Expressions of appreciation or thanks for further contact, while formulaic (Upton \& Connor 2001), are short, utilitarian and devoid of indications of bowing to social rank ('Your consideration of my 
qualifications is appreciated', 'Thank you for your consideration', 'I look forward to hearing from you soon'). The writer persona in American English job application letters cannot be described so much as "paying respect to rank" (Held 1999: 23) as a careful balance between showing interest while not imposing on the reader. It involves managing a writerly stance that is 'equal yet adequately respectful'.

Clearly, the intercultural rhetorical differences in the expression of politeness in job application letters result from different historical contexts. While general principles of politeness may be universal (Brown \& Levinson 1987), the situated application of linguistic politeness strategies and of "sparing or enhancing other's face in order to maintain the "interactive order" vary significantly in terms of "divergent conceptions of face, [...] of what constitutes a face-threatening act/face-flattering act, according to place and era" (Kerbrat-Orecchioni 2011: 136). In this regard, in carrying out IR analysis, it is necessary to be sensitive to each language group's cultural preferences toward one or other type of politeness strategy (face-threatening or face-flattering) rather than assuming only one type of preference exists (e.g., Maier 1992).

The current study examines why and how native-French student writers may fail to express politeness appropriately in the job application letter. Previous work (WillardTraub \& Dressen-Hammouda 2013) has shown that native French-speaking students are often extremely surprised to learn that they have violated politeness expectations in English, because they have in fact made every effort to be polite. It is presumed that such politeness violations occur not because students are unaware of the norms or cannot understand them (Okamura \& Shaw 2000), but having to 'say it that way' can simply cause them to feel discomfort and avoidance, thus leading them to inadvertently violate expected politeness norms by native-English speakers.

\section{Methods}

The present study is the latest phase of a transcultural and transnational teaching and research project I have been collaborating on since 2009, involving student writers from universities in the U.S. and France working together in real-time (both in and out of class) on various writing assignments, using Skype and other Internet technologies (Willard-Traub \& Dressen-Hammouda 2013). This project has fed our thinking about American and French student writers' different perceptions of politeness, and about how and where it occurs in writing.

\subsection{Justification for research design}

As is widely the case across writing research today, IR research combines text linguistic analysis with the qualitative analysis of writing context. Ideally, IR studies "compare similar texts in two languages - L1 and L2 - or texts written by native speakers of a language and those written by second language learners" (Connor 2011: 37). The current study observes rhetorical differences between French and English at two levels: (1) American and French students' reactions to politeness strategies in business letters written and analyzed collaboratively (Willard-Traub \& Dressen-Hammouda 2013); and (2) comparing L1 writing in the two target languages (see Table 2). The interpretation of this study's results builds on these primary observations. 
26 In the current study, a mixed IR research design was used. A move-based lexicogrammatical analysis was carried out on "a local learner corpus" (Seidlhofer 2002) of job application letters produced by L1 French undergraduate writers, focusing on the lexico-grammatical devices the writers used to express politeness in the acts of requesting and thanking in English. The qualitative part of the research examined the student writers' expectations about politeness strategies as well as eight native-English speakers' evaluations of whether or not the strategies chosen by the students were indeed 'polite'. This design choice recognizes the highly complex view of genre (Bhatia 2005; Coe et al. 2002; Devitt 2004; Fairclough 1992; Gee 2005; Hyland 2000; Swales 2004) and contexts for learning genres (Barton et al. 2000; Bazerman 1994; Berkenkotter \& Huckin 1995; Casanave 2004; Johns 1997; Tardy 2009) that have emerged within the past twenty years. Understanding why students write the way they do involves exploring context and situation: a present situation analysis (Flowerdew 2010) of learners' personal situation and the factors that impact their learning, useful for designing writing feedback.

\subsection{Participants and data collection}

27 A total of 69 participants took part in the study. The participants were all undergraduates enrolled in the second year of a Bachelor's degree program in Applied Foreign Languages (Langues Étrangères Appliquées) at Blaise Pascal University in Clermont-Ferrand. The students participated in a semester-long ESP course taught by the author in 2012. To minimize bias, the corpus was coded for effectiveness of politeness strategies by eight native English-speaking raters.

First, students' interpretations of French and American English politeness strategies were gathered during an in-class brainstorming exercise. Students contrastively analyzed a small corpus of French and English job application letters (5 in French, 5 in English; the corpus is partially represented in Table 2). They then participated in a brainstorming activity, where each student was asked to comment on the texts. They were encouraged to speak freely because there were no right or wrong answers. The only constraint placed on the activity was that if someone else had already commented on what they wanted to say, they needed to find something else to comment on. During the brainstorming exercise, the instructor noted down all comments made. After the brainstorming session, students practiced writing job application letters in class, and received immediate oral feedback from the instructor about the effectiveness of their strategies. The following week, brainstorming results were discussed by the whole class within the frame of a cultural component: native-English speaking politeness expectations were explained in context by the instructor, with students comparing to their own expectations.

The corpus of 69 job application letters was constituted three weeks later when the students took an end-of-semester, sit-down exam lasting one hour and thirty minutes. Students received written feedback and a grade, although they did not have the opportunity to later revise. The procedure which produced the corpus is therefore highly contextualized and evidently influenced by classroom interaction. Analysis examined the features of politeness in the acts of requesting and thanking, based on Upton and Connor's (2001) Moves 4 ('requesting an interview') and 5 ('expressing appreciation or thanking'). 
30 Finally, the 69 letter endings were independently evaluated by eight native-English speakers for effectiveness of politeness strategies. All had experience with job application letters, either as L2 writing instructors or because they have had to evaluate them in the line of their own work. Evaluators were asked to rate the politeness of the letter endings on a scale of 1 to 5 , and indicate which words influenced their negative or positive evaluation.

\section{Results and discussion}

\subsection{Student perceptions of politeness in French and English job application letters}

31 The students' analysis of job application letters in French and American English, and subsequent brainstorming session, revealed interesting differences. In contrast to the American English job application letters, for example, students found that there was a more indirect and distanced social relationship portrayed in the French job application letters. They found that the tone tended to be less 'friendly' and 'more distant' than in American English, and that the writer did not show her or his personality. They hypothesized that the French writers' personalities did not come through very much because they were all using largely similar devices: the same formulaic expressions, stock sentences and grammatical structures. In contrast, the amount of effort put into polishing their style and carefully choosing the right vocabulary and turns of phrase was seen to be very important. Likewise, students observed that French writers used a significant number of complex politeness formulas, embedded within what students felt were long sentences. The students thought that the French writers paid more attention to the language than to presenting themselves, in order to distinguish themselves from other candidates. At the same time, they observed that a very formal writing style was used, which was different from spoken French: today one could not speak the way one writes. One student suggested that the style read like "17th century French". In their opinion, the French job application letters seemed "less concrete" than the American English job application letters, in that descriptions of professional experience were linked more to demonstrating polite qualities, rather than to describing that person's prior actions in detail.

In contrast, the students found that writers of American English job application letters created a more direct relationship with the company, by addressing someone in particular (not just 'Monsieur'), showing that they knew the company. In contrast to the French writers, they found that writers of an American English job application letter constructed a longer, more detailed account of their professional activities, focusing on what they have done and know how to do as a result of training and previous experience. They found the writing style more individualized and less standardized, with the writer's personality seeming more apparent as a result. In contrast to French, they felt that each word 'counted', and that each word chosen played a concrete role in describing the writer's previous actions in contrast to the French practice of recreating a formal vision of civilized behavior and demonstrating appropriately polite and deferent behavior. At the same time, they were surprised by the formatting American English authors used - bulleted lists and subheadings - to organize their letter content. One student exclaimed that never in her life would she do 
such a thing in a French job application letter. Others were surprised and intrigued by what they perceived as the writers' ability to showcase and exhibit themselves, which they observed in the amount of detail given about the writers' past experiences and know-how, and pro-active availability.

Thus, two culturally different writer personas (or face-positioning strategies) appear to emerge, as perceived by the students. Resituating the students' observations within the previous discussion of Brown and Levinson (1987), Kerbrat-Orecchioni (2011) and Held (1999), students viewed the writer persona in French as acquiescent and selfwithdrawing. For them, French writers expressed their positive face by reifying a formal, hierarchical relationship with the reader, thus demonstrating they are 'civil' by conforming to the demands of paying respect through face-flattering politeness and formulaic conventions, i.e., submitting to hierarchy and leaving subsequent action up to the reader. In contrast, they sensed that portraying a writer persona in American English would require them to 'exhibit themselves' quite a bit more then in French, demonstrating interest, being optimistic or proposing to help by taking action.

Because politeness devices vary significantly from one culture to the next (minimizing conflict as face-threatening vs. face-flattery), one can hypothesize that the students' lack of familiarity with carrying out the devices of positive face in English would hinder their success in dealing with the demands of negative face: giving deference, being indirect, going on record as incurring a debt (Brown \& Levinson 1987). One might further hypothesize that the conventions for organizing negative face in French showing face-flattery and respect for rank, using gestures of submission - might be recreated in their attempts to mitigate these difficulties. Similarly, if they decided to adopt a more 'Anglo-Saxon' style, it could be hypothesized that they would have a difficult time managing the portrayal of an American-English writer persona, as one who is 'equal yet adequately respectful'. These possibilities are explored in the following description of results, using a moved-based lexico-grammatical analysis of the genre corpus and an evaluative survey about the potential for politeness observation and violation. The survey is revealing because teachers, of course, are not alone in evaluating discoursal norms on the basis of their own cultural experiences. The problem also extends to the foreign companies and human resource managers students communicate with for internships or jobs. Therefore, it can be surmised that the characteristics of this group of non-native writers' texts may similarly influence a real target audience, perhaps in negative ways.

\subsection{Move analysis}

Move analysis of the corpus was based on Upton and Connor's (2001) coding for seven moves in the job application letter. For the purposes of this corpus, I have added one final move, called 'Bringing closure', as in "I look forward to hearing from you" (Tables 3 and 5). Because of its very high frequency (75.4\% of letters contained this particular expression), and formulaic-like homogeneity, Move 8 appeared to play a separate function in the students' purposes for writing, due less to actually showing some sort of real appreciation for hearing back from the reader than simply having a convenient way to bring closure to the letter. The present analysis focuses only on the job application letter ending, represented by Moves 4 through 8 , for the reasons developed in earlier sections of this paper. 
Table 3 Ending moves of learner job application letter corpus

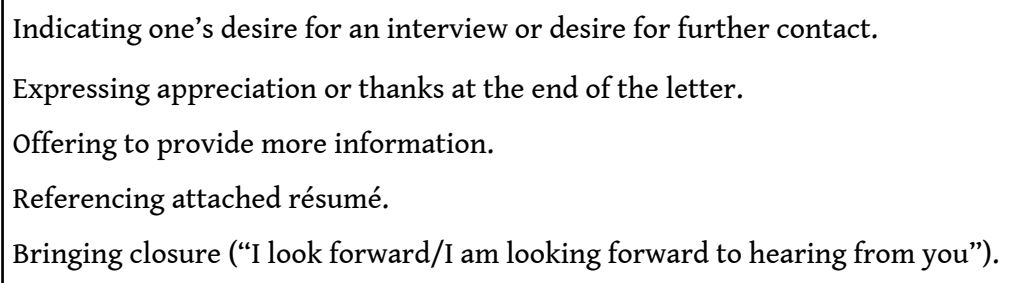

based on Upton \& Connor 2001: 318

The corpus showed a certain degree of variability in the use and ordering of the moves: a total of twenty different move combinations were identified. Of these, three combinations were chosen nearly half of the time: Move $4+$ Move 8 (18.8\%), Move $4+$ Move $7+$ Move 8 (15.9\%), Move $7+$ Move 8 (13\%). Other less frequent choices combined Move $7+$ Move 4 + Move 8 (7.2\%), or just Move 4 or just Move 8 (5.8\%, respectively).

Table 4 Frequency of moves in job application letter endings

\begin{tabular}{|l|l|l|l|l|l|l|l|}
\hline & \multicolumn{2}{|l|}{$\begin{array}{l}\text { \# of endings that } \\
\text { contained }\end{array}$} & $\begin{array}{l}\text { Ending started } \\
\text { with }\end{array}$ & \multicolumn{2}{l}{$\begin{array}{l}\text { Ending contained just } \\
1 \text { move }\end{array}$} \\
\hline $\begin{array}{l}\text { Move 4: Requesting further } \\
\text { contact }\end{array}$ & 48 & $69.6 \%$ & 38 & $55 \%$ & 4 & $5.8 \%$ \\
\hline $\begin{array}{l}\text { Move 5: Expressing appreciation } \\
\text { or thanks }\end{array}$ & 23 & $33.3 \%$ & 7 & $10.1 \%$ & 2 & $2.9 \%$ \\
\hline $\begin{array}{l}\text { Move 6: Offering to provide more } \\
\text { information }\end{array}$ & 4 & $5.7 \%$ & 1 & $1.4 \%$ & 0 & - \\
\hline Move 7: Referencing the resume & 32 & $46.3 \%$ & 19 & $27.5 \%$ & 1 & $1.4 \%$ \\
\hline Move 8: Bringing closure & 52 & $75.4 \%$ & 4 & $5.8 \%$ & 4 & $5.8 \%$ \\
\hline
\end{tabular}

37 A couple of moves were clearly favored by students when constructing the job application letter ending, as can be seen in Table 4: students appeared to think that bringing closure, requesting further contact and making reference to their resume were important tasks. Move 8 ('Bringing closure') was used slightly more than threequarters of the time, followed by Move 4 ('Requesting further contact'), which was used by more than two-thirds of the students. Move 7 ('Referencing the resume') was included by slightly less than half of the students. This preference is further indicated by a number of student writers who either began with these moves (Moves 4 or 7) or constructed the entire letter ending using just one move (Move 4 or Move 8).

What is striking in the analysis of the corpus is the relative paucity of expressions of appreciation or thanking, although one might expect that given the context of having to ask the reader for their consideration, their time, and an interview, showing appreciation or thanking the reader would be important to help balance out the 
imposition and bother created by such a request. However, hardly more than a third of the students chose to include Move 5 in their job application letter (Table 4). What is more, only 17 writers (24.6\%) thanked the reader explicitly, using some form of the word 'thank', meaning that a clear majority $(75.3 \%)$ did not think it necessary to thank the reader outright. A similar avoidance of other politeness markers in English can also be observed: only 33 students used the word 'please' (47.8\%) and only 12 writers (17.4\%) adopted some form of modality to soften their request. In other words, although the students successfully used the moves that were taught in class, a lack of attention to or knowledge about lexico-grammatical conventions ('how to say things politely in English') caused them to end their job application letters in a way which may violate the expectations of an actual reader (e.g., a native English-speaking hiring manager), and thus impact negatively the outcome of their request.

\subsection{Analysis of politeness strategies}

To test for the possibility of this unintended effect, the 69 letter endings were independently evaluated for politeness by eight native-English speakers. Interestingly, the four texts rated the most favorably (R1, R2, R3, R4) showed the most creativity and successful appropriation of the moves, in the sense that the writers constructed the ending beyond a merely mechanical formality. Positively evaluated phrases are shown in bold-faced print; those which raters evaluated negatively are shown in italics:

R1-\#25 (M7) Please find enclosed my Resume outlining my previous experiences and qualifications. (M4-5) I would truly appreciate the opportunity of interviewing for the position. (M5) Thank you for considering my request. (M6) Should you have any questions do not hesitate to contact me. (M8) I am looking forward to your reply.

R2-\#5 (M4-5) Since proven skills are best explained in person, I welcome the opportunity to meet you during an interview. (M4) I will follow up with a call to your office next week. (M5) Thank you for your time and professional courtesy in (M8) reviewing my resume.

R3-\#37 (M7) Please find enclosed my resume which details more fully my qualifications and skills. (M4) I will contact you by mail within a few weeks to see if you have received my application and (M6) if you need further information. (M8) I enthusiastically look forward to hearing from you.

R4-\#9 (M4-5) But because proven skills are best explained in person I welcome the possibility of an interview to introduce myself. (M4) I hope to discuss my desire to be a contributing member of your team soon. (M4) You can contact me at this number from Monday to Saturday: 06.00.00.00.00, or by email.

Also interesting is the observation that the top-rated nine texts explicitly express thanks or appreciation (Move 5), either combining it with previous comments (as in R1R4), or by explicitly fronting the act of thanking:

R5-\#28 I thank you in advance, for the interest and time you have spent looking at my letter. I look forward to hearing from you.

R6-\#58 I am available any time. Please contact me at this number 06.00 .00 .00 .00 or send me an email. Thank you for your consideration. I look forward to hearing from you. R7-\#68 Thank you, I look forward to hearing from you.

R8-\#66 Thank you for taking your time to read this letter.

The next grouping of writers who expressed thanks and/or appreciation was ranked in the middle of the rating range (R26-R28, from 69). In contrast to R1-4, these writers, 
however, showed less creativity and used more formulaic expressions. Their construction of the genre moves was much shorter than R1-4:

R26-\#63 Please find enclosed an up-to-date CV. Thank you for your consideration.

R27-\#40 Thank you in advance for your attention to my application and I am at your disposal for any further information. I'm looking forward to working with you.

R28-\#35 Please find enclosed my up-to-date CV. I am waiting for the opportunity to meet you. Thanks for your consideration.

R29-\#57 You can contact me anytime you want, at 06.00.00.00.00. Thank you for your consideration.

R30-\#42 You will find with my cover letter my resume detailing all my qualifications. Please contact me at this address or at the number above to schedule an interview. I will call your office within 10 days to inquire about my application.

Thank you for your consideration.

All raters noted difficulty in evaluating 'just politeness', as they were also inevitably influenced both by many writers' lack of effectiveness (positioning) and lexicosyntactic inconsistencies (violations of context). As a result, they felt there was often insufficient deference. For example, the raters commented that 'please' was insufficient for creating negative politeness when requesting further contact: the request felt like a command ('Please contact me'). They responded more favorably when there was an additional softening of the imperative ('Please find enclosed', 'Please feel free to contact me'). Similarly, raters often felt that the writers' word choice tended to be 'too imposing' and invasive of the reader's space, failing to leave sufficient room for negotiation. Although 'I will be reached' or 'you can call me' are grammatically correct, these phrases are situationally incorrect when requesting an interview:

R33-\#44 I am available for an interview. I will be reached at the email address and telephone number below. I will call you within a week to inquire on the status of my application. Enclosed my up-to-date CV detailing my qualifications for your consideration. I am looking forward to hearing from you.

R35-\#12 I am of course available for an interview and I am ready to meet you. You can call me everyday after $5 \mathrm{pm}$. Please find enclosed an up-to-date CV for your consideration. I am looking forward to hearing from you.

R39-\#39 I would be pleased to travel to Munich to meet you and be able to talk about my application. Please find an up-to-date CV for your consideration. I look forward to getting an answer from you.

R43-\#69 I would be pleased to meet you in Leeds or Munich, to discuss my application with you. I will call you this week to settle the date. Please find my CV enclosed to this letter. I look forward to hearing from you.

R56-\#29 We can meet in North Brunswick for an interview. I look forward to hearing from you.

Other, less common positioning strategies that also violated raters' politeness expectations include the writers' inclusion of words from other business writing situations that here violate the reader's negative face (prompt consideration/swift reply), or imply an expectation of prompt action ('I wait to hear from you'). In this last case (R67-\#54), however, the writer is in fact falling back on expectations for preserving negative face in French, by making explicit that any expectation for future contact lies in the hands of the reader:

R45-\#59 Thank you for your prompt consideration. I will give you a call within 10 days to follow up. And I will really appreciate to discussing with you.

R55-\#23 Please, find enclosed an up-to-date CV. I'm looking forward to your swift reply. 
R67-\#54 I wait to hear from you. combination, plus their formulation and context of production) that goes into creating a polite interaction. The success with which a writer manages the entire politeness context determines whether or not the reader is able to perceive the writer's intended politeness. Similar to results found by Maier (1992), the factors which appeared to most negatively influence these raters' appreciation were students' unsuccessful realizations of positive face in English ('showing interest', 'being optimistic', 'proposing to help'), which were too direct and conflicted with the readers' negative face needs ('giving deference', being indirect'). The student writers in this study overwhelmingly, although unwittingly, violated those expectations, either by placing inappropriate expectations on the reader or by being improperly informal. Similarly, many students' intent of recreating negative face using the face-flattering strategies and gestures of submission (Kerbrat-Orecchioni 2011; Held 1999), more typical of French business letter writing, was not correctly assessed by raters, who did not perceive such expressions as politeness, but as 'wordiness'.

\section{Conclusion}

The French students' lack of familiarity with the particularities of expressing positive face in English (showing interest, being optimistic, proposing to help) and the concomitant 'equal but adequately respectful' writer persona hindered their attempts to be polite, and caused them to transgress expectations of negative face (giving deference and being indirect). One unexpected result was the surprisingly small number of students who used French rules for managing negative face, perhaps due to the classroom feedback about politeness strategies and expectations in English over the course of the semester. This result shows the contextual permeability of language, and how much linguistic 'appropriateness' depends on understanding the situation and context. Further research will investigate the durability of the students' understanding of positive and negative politeness norms in English over time, by testing the same students for politeness effectiveness during their third-year in the undergraduate program.

Undoubtedly, learning to be polite is anchored in early childhood. It is clear from studies which have examined how children acquire politeness (see Gerholm 2011) that learning politeness strategies is a socialization process whereby children are taught to react to certain emotions (shame, embarrassment, gratitude) and to conform to the behavioral norms concerning those emotions in response to adult demands over time. Learning how to be polite in one's first culture and language is a long-term process, continuing at least up through adolescence, and is intimately implicated in the embodied construction of one's social identity, below the level of consciousness (Bourdieu 1984; Lakoff \& Johnson 1999). As a result, many such patterns are not accessible to conscious analysis or even awareness in one's L1, making the acquisition of L2 politeness norms all the more problematic.

In addition, explicit possibilities for comparative analysis between one's L1 norms and the L2 norms to be learned are few. Typically, cultural components with explicit socialization about how to be polite in the second language are all but absent from the L2 writing classroom, although arguably forms of 'politeness' - and the related 
construction of self in reference to other - underlie all types of writing. Without a doubt, in the L2 writing classroom, much more emphasis is placed on the genres to be mastered and on the overt linguistic strategies used to replicate expected discoursal behavior. In this sense, NNE writers' difficulty in expressing politeness strategies with appropriate linguistic devices in English may stem from their inherent 'knowing' or 'not knowing', and often involves a struggle over the 'truths' of their own identity patterns: what 'feels' right or not (Fox 1994; Ivanič 1998).

The results of this teaching and Intercultural Rhetoric research project underscore the original observation that teaching politeness devices or grammar alone appears far from sufficient to help NNE students improve their effectiveness in L2 writing. As a result, we may need to refine the very idea of writing feedback to find better ways to meet students' needs in acquiring knowledge about such norms, which are essential for later success in intercultural workplace communication. Effective writing feedback cannot be limited to 'after-the-fact comments' written in the margins of student texts, whose meaning can be difficult for students to guess at. Effective writing feedback should be multimodal by nature, and include a variety of interactional settings (oral, written, visual, behavioral) to give students multiple opportunities for learning and gaining awareness of their own cultural thought patterns and assumptions in addition to those of other cultures. In other words, writing feedback should not just be written feedback. To be successful, it might integrate the sort of IR analysis described here into writing feedback, to inform purposeful written responses to student writing, classroom dialogue about cultural politeness norms, dialogue during individual and/or group writing conferences (Harris 1986; Murray 1982), reactions to student comments in class, or the careful design of exercises and their discussion. Other types of writing feedback we have experimented with to prompt student awareness of L2 politeness norms include video-taped responses to student writing, where a native-English speaking writing instructor produced a video recording of her/his reaction to the text, in addition to written feedback (Willard \& Dressen-Hammouda 2013). We have found that such multimodal feedback is particularly effective in eliciting students' awareness of the gap between their own cultural assumptions about how to express politeness in writing and expectations in the L2. Clearly, writing feedback needs to be multimodal, because constructing the self and the other is a long-term, complex process. An IR approach to designing writing feedback is no longer trapped in a deficit model, where NNE writers are just expected to 'fix' and 'adapt' their writing to others' norms. Instead, it intends to heighten students' awareness of L2 norm expectations, including their own L1 expectations, something which most often remains below the level of conscious awareness, including writing instructors' own.

Sincere thanks to two anonymous reviewers for their thoughtful comments and careful reviews, which greatly helped to improve the quality of this paper. 


\section{BIBLIOGRAPHY}

Barton, David, Mary Hamilton and Roz Ivanič (eds.). 2000. Situated Literacies: Reading and Writing in Context. London, UK: Routledge.

Bazerman, Charles. 1994. Constructing Experience. Carbondale: Southern Illinois University Press.

Belcher, Diane and Gayle Nelson (eds.). 2013. Critical and Corpus-based Approaches to Intercultural Rhetoric. Ann Arbor, MI: The University of Michigan Press.

Berkenkotter, Carol and Thomas Huckin. 1995. Genre Knowledge in Disciplinary Communication: Cognition, Culture, Power. Hillsdale, NJ: Lawrence Erlbaum Publishers.

Bhatia, Vijay K. 2005. Worlds of Written Discourse. London, UK: Continuum.

Bhatia, Vijay K. 2008. “Genre analysis, ESP and professional practice.” English for Specific Purposes 27, 161-174.

Bitchener, John and Ute Knoch. 2009. "The value of a focused approach to written corrective feedback." ELT Journal 63, 204-211.

Bourdieu, Pierre. 1984. Distinction: A Social Critique of the Judgment of Taste. Harvard, MA: Harvard University Press.

Brown, Penelope and Stephen Levinson. 1987. Politeness: Some Universals in Language Use. Cambridge: Cambridge University Press.

Casanave, Christine Pearson. 2004. Controversies in Second Language Writing: Dilemmas and Decisions in Research and Instruction. Ann Arbor, MI: The University of Michigan Press.

Chandler, Jean. 2003. "The efficacy of various kinds of error feedback for improvement in the accuracy and fluency of L2 student writing." Journal of Second Language Writing 12, 267-296.

Coe, Richard, Lorelei Lingard and Tatiana Teslenko (eds.). 2002. The Rhetoric and Ideology of Genre: Strategies for Stability and Change. Cresskill, NJ: Hampton.

Connor, Ulla. 1996. Contrastive Rhetoric: Cross-cultural Aspects of Second-language Writing. New York: Cambridge University Press.

Connor, Ulla. 2004. "Intercultural rhetoric research: Beyond texts." Journal of English for Academic Purposes 3, 291-304.

Connor, Ulla. 2011. Intercultural Rhetoric in the Writing Classroom. Ann Arbor, MI: The University of Michigan Press.

Connor, Ulla, and Thomas Upton (eds.). 2004. Applied Corpus Linguistics: A Multidimensional Perspective. Amsterdam: Rodopi.

Davies, Alan, Liz Hamp-Lyons and Charlotte Kemp. 2003. "Whose norms? International proficiency tests in English." World Englishes 22, 571-584.

Devitt, Amy. 2004. Writing Genres. Carbondale: Southern Illinois University Press.

Fairclough, Norman. 1992. Discourse and Social Change. Cambridge: Polity Press.

Ferris, Dana. 2004. “The “"grammar correction”' debate in L2 writing: Where are we, and where do we go from here? (and what do we do in the meantime...?)." Journal of Second Language Writing $13,49-62$. 
Ferris, Dana, Hsiang Liu, Aparna Sinha and Manuel Senna. 2013. "Written corrective feedback for individual L2 writers.” Journal of Second Language Writing 22, 307-329.

Flowerdew, Lynne. 2010. "Devising and implementing a business proposal module: Constraints and compromises." English for Specific Purposes 29, 108-120.

Fox, Helen. 1994. Listening to the World: Cultural Issues in Academic Writing. Urbana, IL: National Council of Teachers of English.

Gee, James. 2005. An Introduction to Discourse Analysis: Theory and Method. London: Routledge. Gerholm, Tove. 2011. "Children's development of facework practices-An emotional endeavor.” Journal of Pragmatics 43, 3099-3110.

Granger, Sylviane, Joseph Hung and Stephanie Petch-Tyson (eds.). 2002. Computer Learner Corpora, Second Language Acquisition and Foreign Language Teaching. Amsterdam: John Benjamins.

Harris, Muriel. 1986. Teaching One-to-One: The Writing Conference. Urbana, IL: NCTE.

Held, Gudrun. 1999. "Submission strategies as an expression of the ideology of politeness: Reflections on the verbalisation of social power relations." Pragmatics 9, 21-36.

Hyland, Ken. 2000. Disciplinary Discourses: Social Interactions in Academic Writing. Harlow, UK: Longman.

Hyland, Ken. 2008. “'Small bits of textual material': A discourse analysis of Swales' writing." English for Specific Purposes 27, 143-160.

Hyland, Ken and Eric Anan. 2006. “Teachers' perceptions of error: The effects of first language and experience." System 34, 509-519.

Hyland, Ken and Fiona Hyland (eds.). 2006. Feedback in Second Language Writing: Contexts and Issues. New York: Cambridge University Press.

Ivanič, Roz. 1998. Writing and Identity: The Discoursal Construction of Identity in Academic Writing. Amsterdam: John Benjamins.

Ivanič, Roz and David Camps. 2001. "I am how I sound: Voice as self-representation in L2 writing." Journal of Second Language Writing 10, 3-33.

Johns, Ann. 1997. Text, Role and Context: Developing Academic Literacies. New York: Cambridge University Press.

Kaplan, Robert. 1966. "Cultural thought patterns in inter-cultural education." Language Learning $16,1-20$.

Kerbrat-Orecchioni, Catherine. 2011. "From good manners to facework: Politeness variations and constants in France, from the Classic Age to today." Journal of Historical Pragmatics 12, 133-155.

Lakoff, George and Michael Johnson. 1999. Philosophy in the Flesh. New York: Basic Books.

Lakoff, Robin. 1973. “The logic of politeness; or, minding Your P's and Q's." In Papers from the Ninth Regional Meeting of the Chicago Linguistic Society. Chicago: Chicago Linguistics Society, 306319.

Maier, Paula. 1992. "Politeness strategies in business letters by native and non-native English speakers.” English for Specific Purposes 11, 189-205.

Murray, Donald. 1982. “The listening eye: Reflections on the writing conference.” Learning by Teaching. Montclair, NJ: Boynton/Cook. 
Okamura, Akiko and Philip Shaw. 2000. "Lexical phrases, culture, and subculture in transactional letter writing." English for Specific Purposes 19, 1-15.

Ramanathan, Vai, and Dwight Atkinson. 1999. "Individualism, academic writing, and ESL writers." Journal of Second Language Writing 8, 45-75.

Rubin, Donald L. and Melanie Williams-James. 1997. "The impact of writer nationality on mainstream teachers' judgments of composition quality." Journal of Second Language Writing 6, 139-154.

Seidlhofer, Barbara. 2002. "Pedagogy and local learner corpora: Working with learning-driven data." In Granger, S., J. Hung and S. Petch-Tyson (eds.), Computer Learner Corpora, Second Language Acquisition and Foreign Language Teaching. Amsterdam: John Benjamins, 213-234.

Swales, John M. 2004. Research Genres: Explorations and Applications. Cambridge: Cambridge University Press.

Tardy, Christine. 2009. Building Genre Knowledge. West Lafayette, IN: Parlor Press.

Truscott, John. 2007. "The effect of error correction on learners' ability to write accurately." Journal of Second Language Writing 16, 255-272.

Truscott, John. 2010. "Some thoughts on Anthony Bruton's critique of the correction debate." System 38, 329-335.

Truscott, John and Angela Yi-ping Hsu. 2008. "Error correction, revision, and learning." Journal of Second Language Writing 17, 292-305.

Upton, Thomas and Ulla Connor. 2001. "Using computerized corpus analysis to investigate the textlinguistic discourse moves of a genre." English for Specific Purposes 20, 313-329.

Willard-Traub, Margaret, and Dacia Dressen-Hammouda. 2013. "Revising voice and identity through Internet-mediated, transnational peer review." Unpublished Manuscript, submitted to Journal of Second Language Writing.

Zhao, Cecilia Guanfang and Lorena Llosa. 2008. "Voice in high-stakes L1 academic writing assessment: Implications for L2 writing instruction.” Assessing Writing 13,153-170.

\section{NOTES}

1. This paper focuses specifically on American English. While the discussion tends to treat American English and French as monocultural entities, this shortcoming is necessary in order to focus more closely on student writing behavior in the classroom. Such small-scale research efforts should be considered first steps in building larger segments of wider data.

\section{ABSTRACTS}

This paper makes the case that writing feedback on grammar error alone is ineffective. Designing more effective writing feedback requires drawing on a broader understanding of the writer's cultural context and present situation. The current study explores this context by using an 
Intercultural Rhetoric approach to examine job application letters written in English by a group of French-speaking undergraduates. A mixed research design was used to investigate the effectiveness of the politeness strategies used in their letters: a move-based lexico-grammatical analysis was combined with qualitative methods (group discussion, survey) to describe the devices students used to express politeness in the acts of requesting and thanking in job application letter endings, and to evaluate whether or not the strategies they chose were indeed 'polite'. Results underscore the fact that teaching politeness devices or grammar alone is far from sufficient to help NNE students improve their effectiveness in writing; writing feedback must be multimodal (oral, written, visual, behavioral). This study contributes to research on writing feedback using Intercultural Rhetoric research.

Cet article part du constat que les commentaires d'enseignant qui portent uniquement sur l'erreur grammaticale semblent inefficaces pour aider les étudiants non anglophones à progresser à l'écrit en anglais. Une conception plus pédagogique des commentaires nécessite une meilleure prise en compte du contexte culturel et de la situation du rédacteur. S'inscrivant dans le cadre de la Rhétorique Interculturelle, la présente étude examine les lettres de motivation écrites en anglais par un groupe d'étudiants de langue française. L'efficacité des stratégies de politesse utilisées dans leurs lettres est évaluée sur deux plans : une analyse lexico-grammaticale des "moves", mais aussi des analyses qualitatives (table ronde, enquête) afin de décrire les dispositifs utilisés pour exprimer la politesse. Il ressort qu'enseigner des formules de politesse par la grammaire seule ne constitue pas une aide suffisante pour permettre aux étudiants d'améliorer leur efficacité à l'écrit en anglais. Les commentaires d'enseignant, pour être efficaces, doivent être multimodaux (oral, écrit, visuel et comportemental).

\section{INDEX}

Mots-clés: anglais américain, commentaire d'enseignant, lettre de motivation, move analysis, politesse, rédacteur de langue française, rhétorique (interculturelle)

Keywords: American English, French student writer, rhetoric (intercultural), job application letter, move analysis, politeness, writing feedback

\section{AUTHOR}

\section{DACIA DRESSEN-HAMMOUDA}

Dacia Dressen-Hammouda is an Associate Professor in ESP at Université Blaise Pascal in Clermont-Ferrand, where she teaches technical and professional communication at Masters and BA levels. She is a member of ACTé Laboratory (EA 4281); her research topics include genre mastery, indexicality, ethnographic approaches, L2 writing research and pedagogy and intercultural rhetoric. She is currently working on the construction of discoursal expertise in novice technical communicators, and on the effects of intercultural exchange on the writer's identity. Her published work includes journal articles (English for Specific Purposes, ASp...) and chapters in several books (Benjamins 2012; Wiley-Black 2013; Peter Lang 2013...).

Dacia.Hammouda@univ-bpclermont.fr 